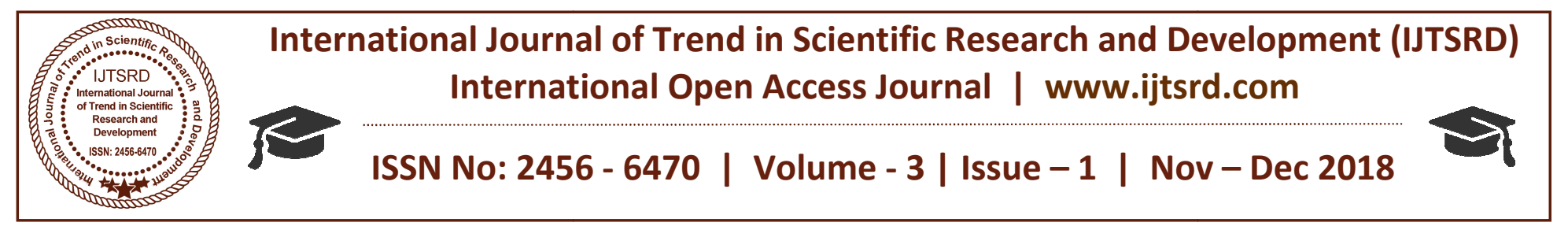

\title{
A Study on Wireless Communication for Radon Concentration Monitoring
}

\author{
Chungyong Kim, Gyu-Sik Kim \\ Department of Electrical and Computer Engineering, University of Seoul, Seoul, Korea
}

\begin{abstract}
As well as the output of radon data using LCDs on pin photodiode radon counters, the stored data is printed on the PC using wired communication, and the data is saved and verified by the server using Wi-Fi communication. WCDMA wireless communication module was also installed to enable radon concentration monitoring in areas where Wi-Fi is not possible. Radon monitoring system that can be selected and applied in different situations was presented through comparison of module price and maintenance cost of WCDMA and Wi-Fi wireless communication.
\end{abstract}

KEY WORDS: radon, Wi-Fi, WCDMA, module price, maintenance cost

\section{INTRODUCTION}

Radon is emitted almost everywhere on earth, but some geographical regions have a higher concentration than others do. Because inhaling radon and its radioactivedecay products causes irradiation of lung tissue, prolonged exposure to a high concentration of radon significantly increases the risk of developing cancer.

There are many commercial instruments and techniques available for measuring radon indoors. In [1], highly sensitive, electrostatic collection chambers using Columbia Resin 39 (CR-39) plastic track detectors were developed for measuring low-level radon. In [2], the unique characteristics and the shortcomings of track detectors for neutron and radon dosimetry is described and compared with those of alternative detector systems. In [3], low-cost alphaparticle sensor systems using special Positive MetalOxide Semiconductor (PMOS) transistors in a floating $\mathrm{n}$-well were developed for radon and radon-daughter monitoring and dosimetry. In [4], a radon detector employed an electrically charged, pressed, porous

metal filter that permitted radon-gas diffusion while blocking ambient light. It readily trapped both attached and unattached Polonium-214 (Po-214) and Polonium 218 (Po-218) ions present in gas passing through the filter. The filter was positively charged relative to the unbiased PN junction of a photo-diode detector within a detection chamber.

There is also much research regarding the measurement of radon concentration in soil gas, water, and indoor air. In [5], results are presented of a preliminary study of radon concentration in soil gas. For the study, AlphaGuard equipment was used to obtain samples from 64 locations within 13 urban areas in Bulgaria from 2008 to 2012. In [6], measurements were taken in Transylvania, in Northwest Romania, of radon concentration in water and indoor air. The measurements were taken using a LUK-VR system for radon gas measurements, a Lucas cell for water, and CR-39 track detectors for indoor air. For our experiments, we used a radon counter with a PIN photodiode radon-sensor module [7]. These radon counters were used to measure the radon concentration of indoor air in houses and workplaces. A radon monitoring and alarm system was also used. The radon concentration data obtained from houses and workplaces was transferred using Wi-Fi and the Internet to a database on a radonmonitoring server system as shown in Fig. 1. 
Fig.1. Block diagram of Wi-Fi based radon monitoring system

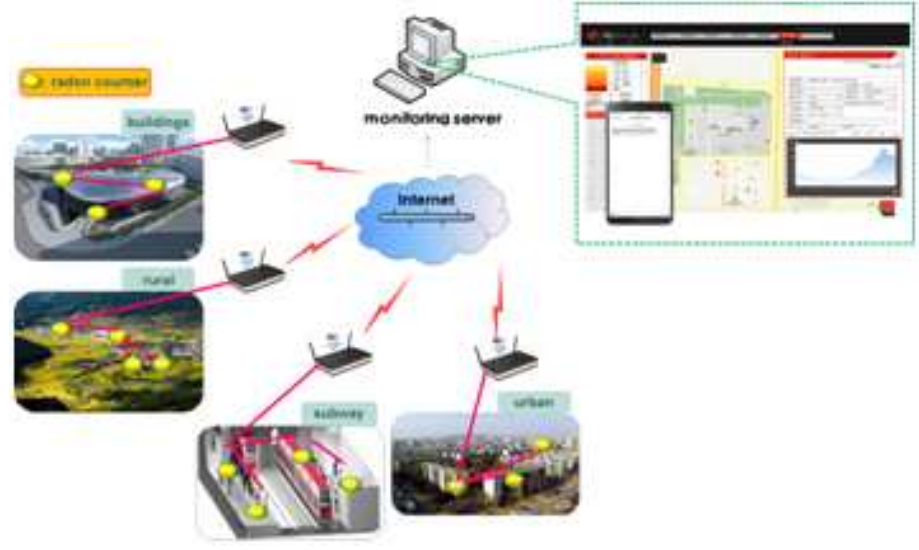

II. PIN PHOTODIODE RADON COUNTER WITH WI-FI MODULE

The ESP8266 Wi-Fi module is a self-contained system-on-chip (SOC) with integrated TCP/IP protocol stacks that can give any microcontroller access to a Wi-Fi network. The ESP8266 is capable of either hosting an application or offloading all Wi-Fi networking functions to another application processor. Each ESP8266 module comes pre-programmed with AT Command Set firmware, meaning the module can be hooked up to an Arduino device with about the same Wi-Fi ability as a Wi-Fi shield. The ESP8266 module is an extremely cost-effective board with a huge, and ever growing, community of users. This module has powerful enough on-board processing and storage capability to allow it to be integrated with the sensors and other application-specific devices through its general-purpose input/outputs (GPIOs), with minimal development up-front and minimal loading during runtime. Its high degree of on-chip integration allows for minimal external circuitry. The front-end module is designed to occupy minimal PCB space. The ESP8266 Wi-Fi module is shown in Fig. 2.

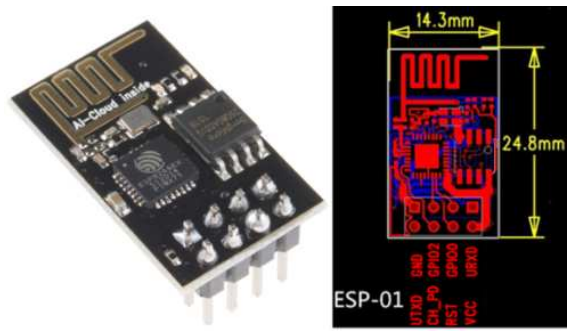

Fig. 2 ESP8266 Wi-Fi module

A commercial PIN photodiode can be used to detect radiation, and particularly, alpha particles. It is low cost, has good quantum efficiency, and good energy resolution. It can also work with a low bias voltage. A PIN photodiode is more widely used than a conventional photomultiplier tube (PMT) because it requires less biasing to operate and it is very compact. The Mega 2560 is a microcontroller board based on the Atmega 2560. It has 54 digital input/output pins (of which 15 can be used as Pulse Width Modulation (PWM) outputs), 16 analog inputs, 4 UARTs (hardware serial ports), a $16 \mathrm{MHz}$ crystal oscillator, a USB port, a power jack, an in-circuit serial programming (ICSP) header, and a reset button. It contains everything needed to support the microcontroller; it just needs to be connected to a computer with a USB cable or powered with an ACto-DC adapter or battery. The Mega 2560 board is compatible with most shields designed for the Uno and the older Duemilanove and Diecimila boards. In our experiments, we used a radon counter assembled from very low-cost consumer electronics. The circuit designs for the power, high voltage generator, LCD, switch, LED, buzzer, microprocessor control unit (MCU), and sensor circuit were made. Using these circuit elements, we developed the PIN photodiode radon-counter printed circuit board (PCB) layout and then assembled the PIN photodiode radon counter shown in Fig. 3. In Fig. 4, the PIN photodiode radon counter installing ESP8266 Wi-Fi module is shown.

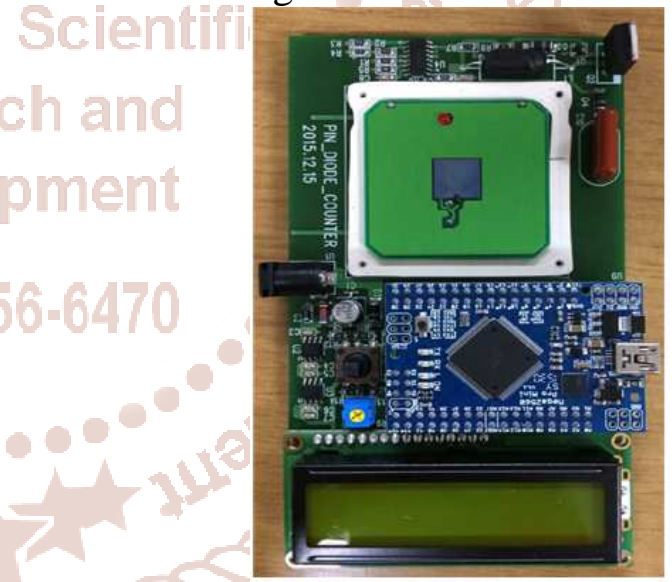

Fig. 3 Implemented PIN photodiode radons counter

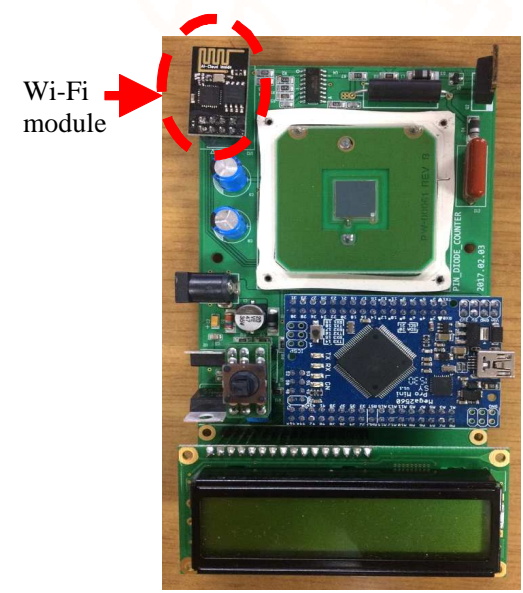

Fig.4. PIN photodiode radon counter with Wi-Fi module 
International Journal of Trend in Scientific Research and Development (IJTSRD) ISSN: 2456-6470

\section{PIN PHOTODIODE RADON COUNTER WITH WCDMA MODULE}

Wideband Code Division Multiple Access (WCDMA) is a third-generation ( $3 \mathrm{G})$ standard that employs the direct-sequence code division multiple access (DSCDMA) channel access method and the frequencydivision duplexing (FDD) method to provide highspeed and high-capacity service. WCDMA is the most commonly used variant of the Universal Mobile Telecommunications System (UMTS). It was developed by Japan's NTT DoCoMo and formed the basis of its Freedom of Multimedia Access (FOMA) 3G Network. Fig. 5 and Fig. 6 show the parameters and the frequency utilization of WCDMA, respectively.

\begin{tabular}{|c|c|}
\hline Channel bandwidth & $5 \mathrm{MHz}$ \\
\hline Duplex mode & FDD and TDD \\
\hline Downlink RF channel structure & Direct spread \\
\hline Chip rate & $3.84 \mathrm{Mbps}$ \\
\hline Frame length & $10 \mathrm{~ms}$ \\
\hline Spreading modulation & $\begin{array}{l}\text { Balanced QPSK (downlink) } \\
\text { Dual-channel QPSK(uplink) } \\
\text { Complex spreading circuit }\end{array}$ \\
\hline Data modulation & $\begin{array}{l}\text { QPSK (downlink) } \\
\text { BPSK (uplink) }\end{array}$ \\
\hline Channel coding & Convolutional and turbo codes \\
\hline Coherent detection & $\begin{array}{l}\text { User dedicated time multiplexed pilot (downlink } \\
\text { and uplink). common pilot in the downlink }\end{array}$ \\
\hline Channel multiplexing in downlink & Data and control channels time multiplexed \\
\hline Channel multiplexing in uplink & $\begin{array}{l}\text { Control and pilot channel time multiplexed } \\
\text { I\&Q multiplexing for data and control channel }\end{array}$ \\
\hline Multirate & Variable spreading and multicode \\
\hline Spreading factors & 4-256 (uplink), 4-512 (uplink) \\
\hline Power control & Open and fast closed loop $(1.6 \mathrm{kHz})$ \\
\hline Spreading (downlink) & $\begin{array}{l}\text { OVSF sequences for channel separation } \\
\text { Gold sequences } 2^{18}-1 \text { for cell and user separation } \\
\text { (truncated cycle } 10 \mathrm{~ms} \text { ) }\end{array}$ \\
\hline Spreading (uplink) & $\begin{array}{l}\text { OVSF sequences, Gold sequence } 2^{41} \text { for user } \\
\text { separation (different time shifts in I and Q channel, } \\
\text { truncated cycle } 10 \mathrm{~ms} \text { ) }\end{array}$ \\
\hline Handover & $\begin{array}{l}\text { Soft handover } \\
\text { Interfrequency handover }\end{array}$ \\
\hline
\end{tabular}

Fig.5. Parameters of WCDMA

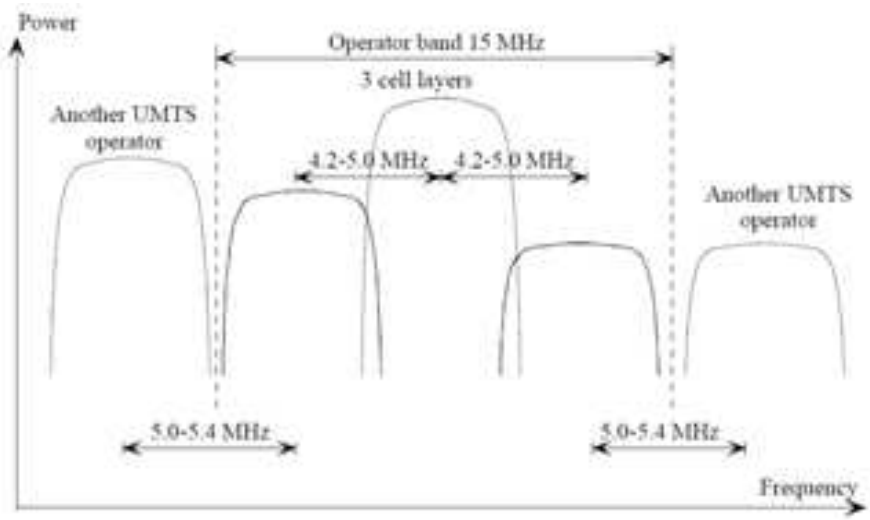

Fig.6. Frequency utilization with WCDMA

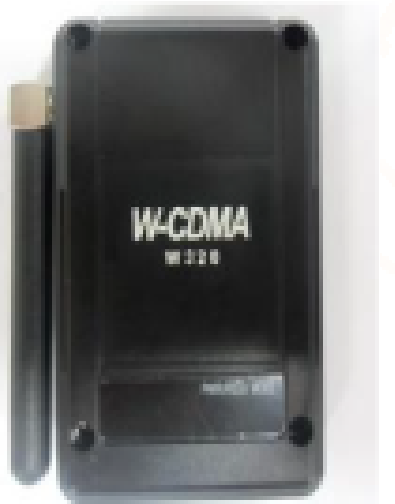

Fig.7. KEM-W320 modem 


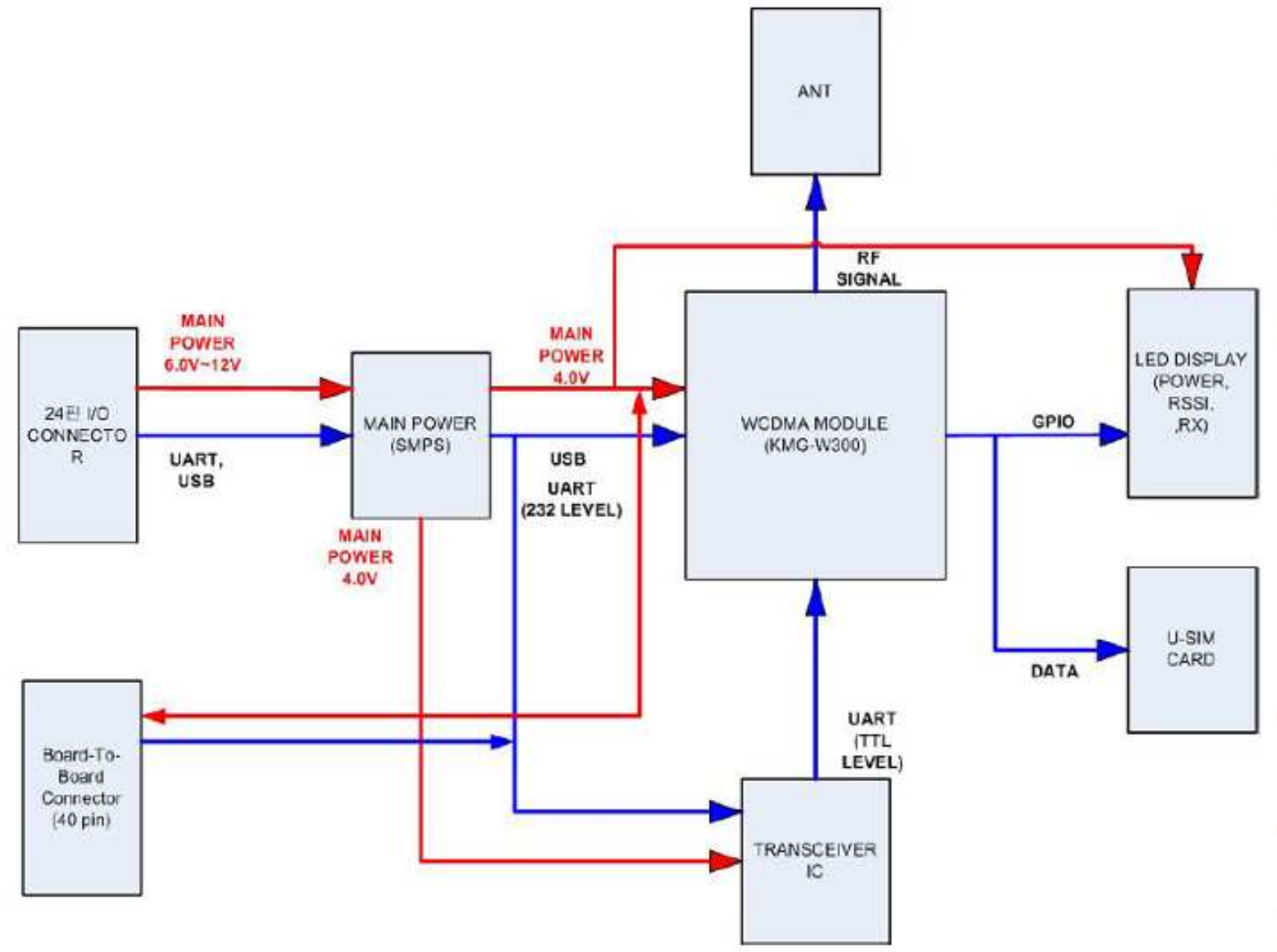

Fig.8. KEM-W320 block diagram

The KEM-W320 modem chosen in this study for wireless communication of radon data and its block diagram are shown in Fig. 7 and Fig. 8, respectively.

\section{OPERATING EXPENSE AND COST COMPARISON OF WI-FI AND WCDMA MODULES}

Wi-Fi wireless communications should be based on Wi-Fi sharing and Internet access, but it cannot be available for some rural or mountainous areas to connect to $\mathrm{Wi}-\mathrm{Fi}$. Just as mobile phones can be used anywhere in the world, WCDMA wireless communication can also be covered by Wi-Fi. However, there are disadvantages of having large size, expensive module price and high maintenance cost compared to Wi-Fi. While the size of the WCDMA wireless terminal shown in Figure 7 is almost as large and heavy as a mobile phone, Wi-Fi chips have a light benefit as nail-sized as shown in Figure 4. The retail price of KEM-W320 is about 100 US dollars, while the ESP8266 Wi-Fi module is about 4 US dollars. The maintenance fee is 44 US dollars/year for the KEM-W320, but the Wi-Fi module has the advantage of having no additional charge.

\section{CONCLUDING REMARKS}

In this paper, a radon counter using a PIN photodiode radon-sensor module was discussed. For our experiments, we used a radon counter with a PIN photodiode radon-sensor module. Using electrostatic collection and the PIN photodiode, a high sensitivity radon detector for air has been developed.

As well as the output of radon data using LCDs on pin photodiode radon counters, the stored data is printed on the PC using wired communication, and the data is saved and verified by the server using Wi-Fi communication. WCDMA wireless communication module was also installed to enable radon concentration monitoring in areas where $\mathrm{Wi}-\mathrm{Fi}$ is not possible. Radon monitoring system that can be selected and applied in different situations was presented through comparison of module price and maintenance cost of WCDMA and Wi-Fi wireless communication. 


\section{ACKNOWLEDGMENT}

This work was also supported by the National Research Foundation of Korea (NRF) grant funded by the Korea government (MSIP) (No. 2016011249).

\section{REFERENCES}

1. Hiroshi Miyake, Keiji Oda and Masami Michijima, "Portable and high-sensitive apparatus for measurement of environmental radon using CR-39 track detector," Japanese Journal of Applied Physics, Vol.26, No.4, pp.607-610, April, 1987

2. L. Tommasino, "Importance of track detectors in radiation dosimetry," Nucl. Tracks Radiat. Meas., Vol.22, No.1-4, pp.707-717, 1993

3. T. Streil, R. Klinke, W. Birkholz, and G. Just, "New alpha radiation detection systems for radon and radon daughter monitoring," Radiation Measurements, Vol.25, No.1-4, pp.621-622, 1995
4. Peter J. Diamondis, "Radon gas measurement apparatus having alpha particle-detecting photovoltaic photodiode surrounded by porous pressed metal daughter filer electrically charged as PO-219 ion accelerator," US patent, P.N. 5489780, Feb. 1996

5. Bistra Kunovska, Kremena Ivanova, Zdenka Stojanovska, Daniel Vuchkov, and Nadia Zaneva, "Measurements of radon concentration in soil gas of urban areas, Bulgaria," Rom. Journ. Phys., Vol.58, Supplement, 2013, pp.s172-s179

6. D. C. Nita, M. Moldovan, T. Sferle, V. D. Ona, and B. D. Burghele, "Radon concentrations in water and indoor air in north-west regions of Romania," Rom. Journ. Phys., Vol.58, Supplement, 2013, pp.s196-s201

7. Gyu-Sik Kim, Tae-Gue Oh and Jae-Hak Kim, "Implementation of a PIN photodiode radon counter," Global Journal of Engineering Science and Researches, Vol.3, No.1, Jan., 2016, pp.58-63 